\title{
Viabilidad del polen de Ricinus communis L. "higuerillas" presentes en el campus de la Universidad Nacional José Faustino Sánchez Carrión Feasibility of fig pollen Ricinus communis L. "higuerillas" present on the campus of the
José Faustino Sánchez Carrión National University
}

\author{
Andy Paolo Santa Cruz Ventura', Anthony Apolinario Cortez Lázaro', Ángel David Hernández Amasifuen ${ }^{1}$, José Luis Romero
} Bozzetta

\begin{abstract}
RESUMEN
Objetivo: Determinar la viabilidad del polen de la higuerilla presente en el campus de la Universidad Nacional José Faustino Sánchez Carrión, con miras a emplearse en programas de mejoramiento genético. Materiales y Métodos: Se empleó polen de higuerilla recolectada del campus de la universidad, y fueron llevadas a los laboratorios multifuncionales para su tinción con orceína acética. Resultados: Con el método de tinción se logró identificar los gramos de polen fertiles, obteniendose una viabilidad polínica mayor a $86 \%$. Conclusión: Se logró determinar la viabilidad del polen de la higuerilla presente en el campus de la Universidad Nacional José Faustino Sánchez Carrión, obteniendo 88,44\% de viabilidad polínica promedio.
\end{abstract}

Palabras clave: Ricinus communis, higuerrila, polen, viabilidad.

\section{ABSTRACT}

Objective: To determine the viability of the pollen of the fig tree present on the campus of the José Faustino Sánchez Carrión National University, with a view to being used in genetic improvement programs. Materials and Methods: Fig pollen collected from the university campus was used, and they were taken to multifunctional laboratories for staining with acetic orcein. Results: With the staining method it was possible to identify the grams of fertile pollen, obtaining a pollen viability greater than $86 \%$, Conclusion: It was possible to determine the viability of the higuerilla pollen present on the campus of the José Faustino Sánchez Carrión National University, obtaining $88.44 \%$ of average pollen viability.

Keywords: Ricinus communis, higuerrila, pollen, viability.

\section{INTRODUCCIÓN}

La calidad del polen es de gran importancia en las investigaciones relacionadas con la reproducción sexual, pues permiten asegurar el éxito de las hibridaciones e incrementar la eficiencia del mejoramiento. El medio ambiente en condiciones adversas puede afectar la viabilidad del polen limitando la producción de la semilla botánica. El estrés de calor y frío provocan una disminución de la cantidad y calidad del polen, lo que puede ser ocasionado por una menor cantidad de nutrientes presentes en la antera, así como una reducción importante en el número de granos formados como consecuencia del elevado porcentaje de aborto de células madre de polen y de microsporas en diferentes etapas de su formación (Camarena, Chura y Blas, 2014).

La "higuerilla"; Ricinus communis L. es una planta que se encuentra distribuida desde el nivel del mar hasta los $3000 \mathrm{msnm}$. Se encuentra en los bordes de los caminos, de las quebradas y de los ríos, en huertas y también sembrada en cultivos comerciales con todas las normas técnicas de la agricultura moderna. Es de tipo arbustiva de tallo grueso y leñoso, puede presentar una coloración púrpura en sus hojas, las cuales son alternas y presentan gran tamaño, nerviación palmeada con bordes irregulares dentados y un peciolo largo (Mazzani, 2007). Presenta inflorescencias, encontrándose las flores masculinas en la parte inferior con múltiples estambres soldados. Mientras que en la parte superior se encuentran las flores femeninas. Esta planta presenta un ciclo de vida anual o perenne, y su floración es casi todo el año. A la vez es una planta cultivada en algunas regiones por el aceite de sus semillas. Pero a su vez son altamente tóxicas (Samoyoa, 2007).
El fruto es globuloso, trilobulado, casi siempre cubierto por abundantes púas, que le dan un aspecto erizado: tiene tres cavidades, cada una con una semilla, la cual contiene una toxina llamada ricina. Al secarse los frutos, la cubierta espinosa se tensa progresivamente produciendo finalmente un efecto de resorte que lanza la semilla a distancias superiores a los diez metros, siendo ésta la forma de esta planta para extenderse (Mazzani \& Rodriguez, 2009).

La higuerilla es una planta diploide con un número cromosómico de 20. Este conocimiento de su genética a permitir que se iniciara en los avances de mejora genética y en la actualidad aún más por el gran valor para la producción de biocombustibles, la cual se obtiene a partir del aceite de ricino, que presenta gran densidad, conserva su viscosidad a diferentes temperaturas y se congela $\mathrm{a}-10{ }^{\circ} \mathrm{C}$ (Valderrama, Mery y Aravella, 1994; Shaheen, 2002).

Desde 1936 en Brasil se ha ido desarrollando mejoras de este cultivo, para obtener variedades de mayor producción y sobre todo solucionar el problema dehiscencia de los frutos. En la década de los 70 en la India se logra el primer híbrido, el cual llega a presentar $120 \%$ de mayor productividad. Seguidamente continuaron en la búsqueda de resistencia o tolerancia al nematodo reniforme, Fusarium oxisporium f. sp ricini, Botrytis cinerea, y finamente que presente tolerancia a la salinidad del suelo. (Goytia-Jimenez et al., 2011).

A finales de los 90' China ya presentaba híbridos con precocidad, porte bajo, mayor rendimiento, alto contenido de aceite, semidehiscencia o indehiscencia, resistencia o tolerancia a enfermedades (Mazzani, 2007). En la actualidad se continúa con los programas de mejora genética en higuerilla en países como México, Colombia y Uruguay, enfocándose en mayor parte al 
incremento de contenido de aceite para la producción de biodiesel. Todos estos programas vienen desarrollando todo tipo de tecnología para la identificación de nuevas variedades, incluyendo los cultivos de tejidos y marcadores moleculares (Benavides, Benjamin y Pashova, 2007).

Además, cabe señalar, que dentro de los programas de mejora a partir de cultivo de tejidos se viene empleando el cultivo de anteras y microsporas, lo que permite obtener plántulas que pueden expresar genes recesivos, al ser haploides y luego por duplicación cromosómica con colchicina tener una planta doblehaploide. De esta manera se pueden lograr expresiones genes que podrían ser valiosos para la mejora de este tipo de cultivo, y también acortando el tiempo de tener una línea pura por métodos tradicionales (Camarena et al., 2014).

Por lo tanto, el objetivo de la presente investigación fue determinar la viabilidad del polen de la higuerilla presente en el campus de la Universidad Nacional José Faustino Sánchez Carrión, con miras a emplearse en programas de mejoramiento genético.

\section{MATERIALES Y MÉTODOS}

La presente investigación se desarrolló en los laboratorios multifuncionales de la Escuela Profesional de Biología con mención en Biotecnología, Universidad Nacional José Faustino Sánchez Carrión, Huacho, Huaura, Lima, Perú.

Las muestras fueron recolectadas de inflorencias de higuerillas presentes en el campus de la Universidad en sobres de papel manteca y posteriormente fueron llevadas a los laboratorios, donde se procedió a colocarlas en porta objetos y seguidamente se realizó la tinción con orceína acética al $2 \%$. Después se colocó un cubre objetos y se llevó al microscopio para la observación en aumento de 100x a 400x (Fig. 1). La observación y evaluación constó de contar el número de polen teñido y no teñidos en unos 10 campos ópticos por cada muestra.

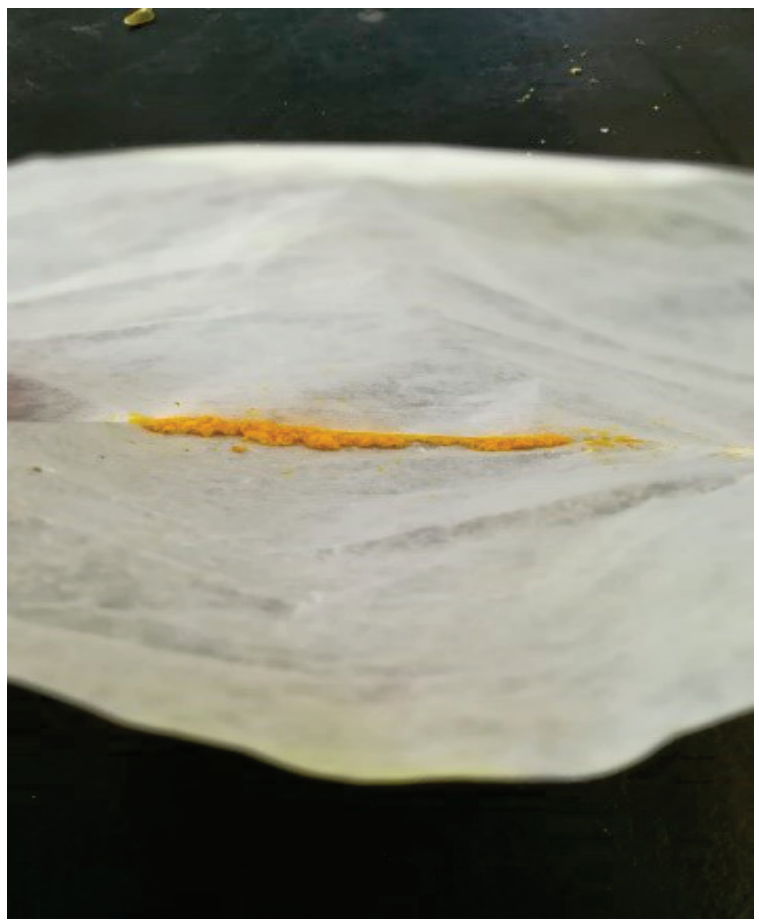

Figura. Muestras recolectadas de higuerilla

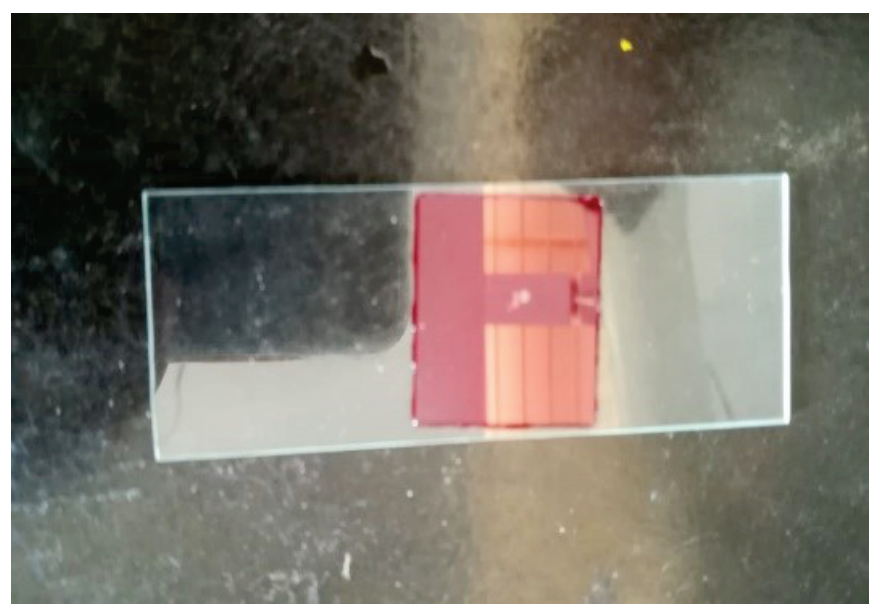

Figura 2. Muetras colocadas en porta objetos y teñidas con orceína acética al $2 \%$.

\section{RESULTADOS}

El método de tinción permitió la coloración de los granos de polen fértiles y los que no presentaron coloración se consideraron infértiles (Fig. 3). Se puede apreciar las diferentes observaciones por campos y repeticiones, y a partir de estos resultados se obtuvo $88,44 \%$ de viabilidad polínica promedio (Tabla 1).

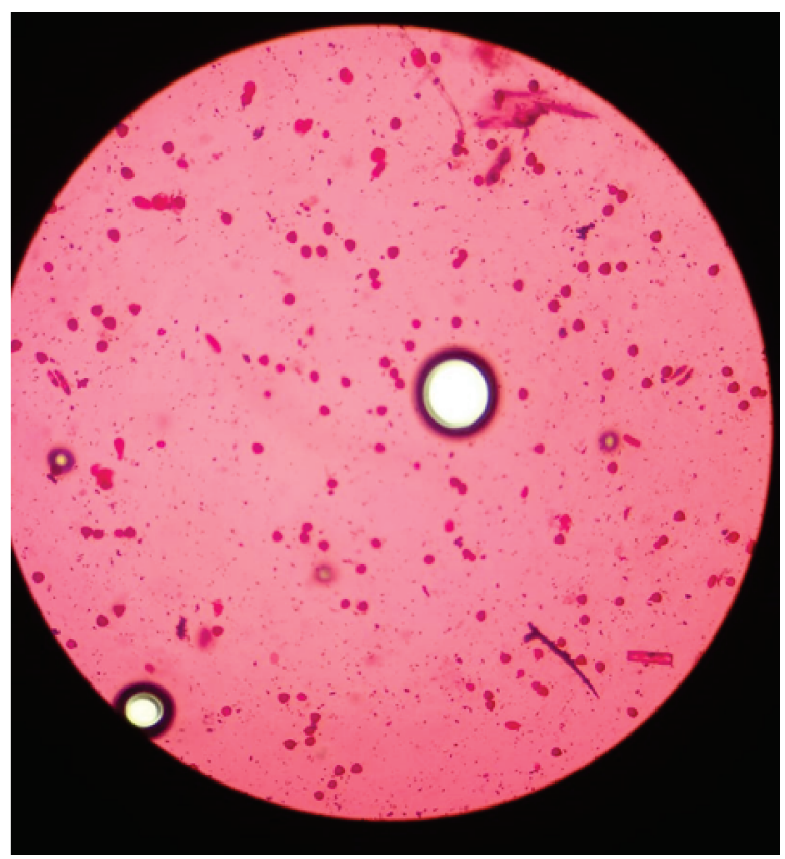

Figura 3. Granos de polen de Ricinus communis L. "higuerilla" teñidos con orceína acética al $2 \%$. 
Tabla 1.

Porcentaje de viabilidad de polen de Ricinus communis L. "higuerilla" .

\begin{tabular}{cccc}
\hline Muestra & $\begin{array}{c}\text { Polen } \\
\text { Teñido }\end{array}$ & $\begin{array}{c}\text { Polen no } \\
\text { Teñido }\end{array}$ & $\begin{array}{c}\text { Viabilidad } \\
(\%)\end{array}$ \\
\hline 1 & 221 & 29 & 88,40 \\
2 & 216 & 34 & 86,40 \\
3 & 222 & 28 & 88,80 \\
4 & 228 & 22 & 91,20 \\
5 & 225 & 25 & 90,00 \\
6 & 217 & 33 & 86,80 \\
7 & 223 & 27 & 89,20 \\
8 & 215 & 35 & 86,00 \\
9 & 218 & 32 & 87,20 \\
10 & 226 & 24 & 90,40 \\
\hline & Promedio & & $\mathbf{8 8 , 4 4}$
\end{tabular}

\section{DISCUSIÓN}

Los resultados obtenidos mostraron una viabilidad del polen de Ricinus communis L. "higuerilla" del $88,44 \%$, esto podría estar en relación a las condiciones óptimas de temperatura y humedad que requiere la planta como son las presentes en inicios del mes de abril, ya que a temperaturas de $25^{\circ} \mathrm{C}$ y humedad del $80 \%$ permiten una mayor liberación y viabilidad del polen, mientras que por debajo de los $10^{\circ} \mathrm{C}$ se pierde la viabilidad del polen. Además de que en ambientes con humedad muy elevada puede generar perdida del vigor y viabilidad del polen, e incluso podría germinar dentro de las anteras antes de su apertura, considerando que el polen de higuerilla tiene una viabilidad aproximada de una semana, conservarlo por más días afectaría su morfología normal e iría perdiendo su potencialidad para germinar en el tiempo (Goytia-Jimenez et al., 2011).

Se debe considerar que la viabilidad del polen puede variar considerablemente entre individuos de una sola especie y entre muestras de un individuo. $Y$ también se debe tener en cuenta que la orceína acética sobrestima la viabilidad del polen, pero da información adicional de la morfología nuclear. Este método se puede utilizar para la discriminación cuando se tienen muchos genotipos, pues tiene la ventaja de permitir hacer predicciones rápidas de la fertilidad masculina. Por lo que tiene antecedentes que las tinciones morfológicas no son una buena técnica de medida de la fertilidad real, pero permiten detectar diferenciar entre granos de polen abortados y no abortados y su utilidad es fundamentalmente en los estudios de androesterilidad, para conocer el diámetro del polen y para conocer la dotación cromosómica (Mendes et al., 2009).

\section{CONCLUSIÓN}

Se logró determinar la viabilidad del polen de la higuerilla presente en el campus de la Universidad Nacional José Faustino Sánchez Carrión, obteniendo $88,44 \%$ de viabilidad polínica promedio.

\section{REFERENCIAS BIBLIOGRÁFICAS}

Benavides A., Benjumea P. y Pashova V. (2007). El Biodiesel de aceite de higuerilla como combustible alternativo para motores diesel. Dyna, Año 74, No. 153, pp 141-150, Medellín, Colombia.

Camarena, F., Chura J. y Blas R. (2014). Mejoramiento genético y biotecnológico de plantas. Promotora Lima. Perú.

Goytia-Jimenez M.A., Galeegos-Goytia C.H. y Nuñez-Colin C.A. (2011). Relación entre variables climáticas con la morfología y contenido de aceite de semillas de higuerilla (Ricinus communis L.) de Chiapas. Revista Chapingo, 17(1): 41-48.

Mazzani E. (2007). El Tártago: La planta, su importancia y usos. Revista Digital del Centro Nacional de Investigaciones Agropecuarias. Maracay Venezuela.

Mazzani E. y Rodriguez E. (2009). Estudio de la variabilidad presente en germoplasma de tártago (Ricinus communis L.) en cuanto a racimos, frutos y semillas. Revista UDO Agrícola 9 (4): 764-769.

Mendes R.C., Dias D.C., Pereira M.D. y Berger P.G. (2009). Tratamentos pré-germinativos em sementes de mamona (Ricinus communis L.). Revista Brasileira de Sementes, 31(1): 187-194.

Samayoa M. (2007). Manual Técnico del Higuerillo. Ministerio de agricultura y ganadería El Salvador C.A. Centro Nacional de Tecnología Agropecuaria y Forestal, CENTA. Programa Agroindustrial.

Shaheen A.M. (2002). Morphological variation within Ricinus communis L. in Egypt; Fruit, Leaf, Seed and Pollen. Pakistan Journal of Biological Science. 5 (11): 1202-1208.

Valderrama J., Mery A. \& Aravena F. (1994). La higuerilla y su principal producto: Aceite de ricino. Parte 1. Aspectos generales. Información Tecnológica, 5(1): 87 - 90. Santiago de Chile. 